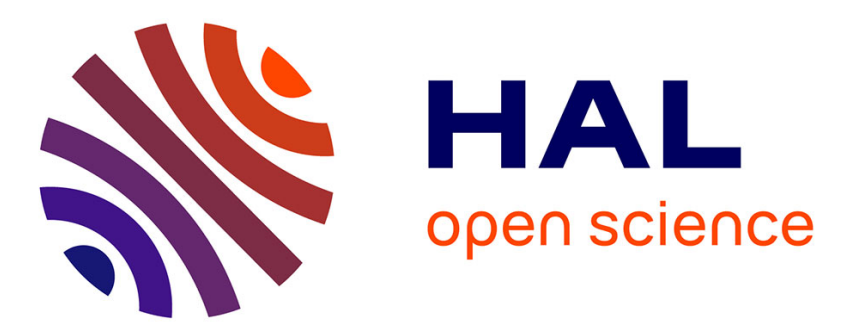

\title{
Three-dimensional face stability analysis of circular tunnels by numerical simulations
}

Daniel Dias, Jean-Pierre Janin, Abdul-Hamid Soubra, Richard Kastner

\section{To cite this version:}

Daniel Dias, Jean-Pierre Janin, Abdul-Hamid Soubra, Richard Kastner. Three-dimensional face stability analysis of circular tunnels by numerical simulations. ASCE Geocongress 2008, 2008, Nouvelle Orléans, United States. 10.1061/40972(311)111 . hal-01009049

\section{HAL Id: hal-01009049 https://hal.science/hal-01009049}

Submitted on 23 Jun 2018

HAL is a multi-disciplinary open access archive for the deposit and dissemination of scientific research documents, whether they are published or not. The documents may come from teaching and research institutions in France or abroad, or from public or private research centers.
L'archive ouverte pluridisciplinaire HAL, est destinée au dépôt et à la diffusion de documents scientifiques de niveau recherche, publiés ou non, émanant des établissements d'enseignement et de recherche français ou étrangers, des laboratoires publics ou privés. 


\title{
Three-dimensional face stability analysis of circular tunnels by numerical simulations
}

\author{
Daniel Dias ${ }^{1}$, M. ASCE, Jean-Pierre Janin ${ }^{2}$, Abdul-Hamid Soubra ${ }^{3}$, M. ASCE, and \\ Richard Kastner ${ }^{4}$
}

\footnotetext{
${ }^{1}$ Associate Professor, INSA Lyon, LGCIE Site Coulomb3, 69621 Villeurbanne Cedex, France. E-mail: daniel.dias@insa-lyon.fr,

${ }^{2}$ Post Graduate, INSA Lyon, LGCIE Site Coulomb3, 69621 Villeurbanne Cedex, France. E-mail: jeanpierre.janin@insa-lyon.fr,

${ }^{3}$ Professor, University of Nantes, GeM, UMR CNRS 6183, Bd. de l'université, BP 152, 44603 SaintNazaire cedex, France. E-mail: Abed.Soubra@univ-nantes.fr

${ }^{4}$ Professor, INSA Lyon, LGCIE Site Coulomb3, 69621 Villeurbanne Cedex, France. E-mail: richard.kastner@insa-lyon.fr
}

\begin{abstract}
The face stability analysis of shallow circular tunnels driven by the pressurized shield is investigated by three-dimensional numerical simulations. Both the active and passive soil failures of the tunnel face are considered in the analysis. A comparison is performed between (i) the present numerical solutions of the ultimate pressure of the tunnel face, (ii) the results of the multiblock mechanism of the kinematical approach in limit analysis and (iii) the values of the ultimate tunnel pressure obtained from centrifuge model tests. The shortcomings of the multiblock failure mechanism are presented and discussed.
\end{abstract}

\section{INTRODUCTION}

The face stability analysis of shallow circular tunnels driven by the pressurized shield has been investigated in literature by several authors. Most approaches are based on a two-dimensional analysis (Dias et al. 2002, DeBorst et al. 1996) and are based on either the limit equilibrium (Anagnostou 1996) or the limit analysis methods (Leca and Dormieux 1990, Soubra 2000, 2002) which require a priori assumptions concerning the form of the failure mechanism. In the three-dimensional two-block failure mechanism investigated by Leca and Dormieux (1990), the assumed failure mechanism considers that only a part of the tunnel circular face (an ellipse inscribed in that circular area) is concerned by failure; the remaining part of the tunnel face surface being at rest. The aim of the present work is to determine the ultimate tunnel pressure and the corresponding soil mass at failure without any a priori hypotheses concerning the shape of the failure mechanism. The approach used in the present paper for the determination of the ultimate pressure of the tunnel face is based on numerical 
simulations using the Lagrangian explicit finite difference code FLAC ${ }^{3 D}$. Both the active and passive soil failures in front of the tunnel face are considered in the analysis. The ultimate tunnel pressures obtained in both the active and passive cases are presented and compared (i) to those given by the kinematical approach of limit analysis by Soubra (2002) using a multiblock failure mechanism and (ii) to the results of the centrifuge model tests by Al-Hallak (1999). In the following, one presents an overview of the recent literature. Then, the numerical FLAC ${ }^{3 \mathrm{D}}$ simulations and the comparison between the present solutions and the existing ones follow.

\section{OVERVIEW OF RECENT LITERATURE ON THE ULTIMATE PRESSURE OF THE TUNNEL FACE}

Several theoretical models have been presented in literature for the computation of the ultimate tunnel pressure. The most recent approach is the one presented by Leca and Dormieux (1990) and improved later by Soubra (2000, 2002). The model by Soubra (2002) is based on the kinematical approach of the limit analysis theory and used a multiblock failure mechanism. The results given by this mechanism are the best upperbound solutions for both the active and passive cases. On the other hand, centrifuge model tests have been performed by Al-Hallak (1999). The centrifuge model is composed of a steel container of dimensions $1200 \mathrm{~mm} \times 80 \mathrm{~mm} \times 720 \mathrm{~mm}$ filled with Fontainebleau's sand and a steel tube of $200 \mathrm{~mm}$ diameter to represent the tunnel. The tunnel axis is located at $500 \mathrm{~mm}$ below the surface of the soil mass. In these tests, the small-scale model is submitted to an acceleration of $50 \mathrm{~g}$ where $\mathrm{g}$ is the gravitational acceleration. This model simulates a tunnel of $10 \mathrm{~m}$ diameter.

Three phases are performed during the test for the determination of the ultimate active pressure: First, an air pressure equals to that corresponding to the earth pressure at rest at the tunnel center is applied to the tunnel face. Then, the acceleration is increased from $1 \mathrm{~g}$ to $50 \mathrm{~g}$. Finally, the ultimate active tunnel pressure is obtained by reducing the supporting pressure until failure occurs. The experimental results have shown that in the active case, the soil mass at failure does not reach the ground surface and the failure mechanism is confined nearby the tunnel face. However, the soil mass in failure reaches the ground surface in the passive case.

\section{THE NUMERICAL APPROACH}

The centrifuge model tests performed by Al-Hallak on a small-scale model of tunnel were simulated using the explicit finite difference code FLAC ${ }^{3 \mathrm{D}}$. For symmetry reasons, only half of the geometry is modeled (figure 1). The size of the numerical model is $0.4 \mathrm{~m}$ in the $\mathrm{X}$ direction, $0.72 \mathrm{~m}$ in the $\mathrm{Z}$ direction and $0.90 \mathrm{~m}$ in the $\mathrm{Y}$ direction. These dimensions are chosen so as not to affect the value of the ultimate tunnel pressure. A three-dimensional non uniform mesh is used. The present model is composed of approximately 23000 zones. A conventional elastic-perfectly plastic model based on the Mohr-Coulomb failure criterion is adopted to represent the soil. The parameters of the soil mass were deduced from laboratory tests (Gay 2000, 
Gaudin 2002). The metallic tube simulating the tunnel is simulated by a "liner" structural element. The tunnel is assumed to be rigid and an interface is placed between the soil and the outer surface of the tunnel to allow the slip that may occur on this contact area.

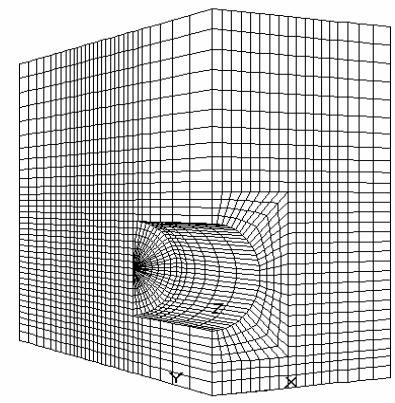

FIG. 1. Numerical model

The characteristics adopted in the numerical simulations for the soil and the interface are given in Table 1.

Table 1. Characteristics of the soil and the interface

\begin{tabular}{|l|l|}
\hline Soil characteristics & Value \\
\hline Young Modulus & $50 \mathrm{MPa}$ \\
\hline Poisson's ratio & 0.33 \\
\hline Cohesion & $0 \mathrm{kPa}$ \\
\hline Friction angle $\varphi$ & $42^{\circ}$ \\
\hline Dilatancy angle $\psi$ & $15.3^{\circ}$ \\
\hline Unit weigth $\gamma$ & $15.7 \mathrm{kN} / \mathrm{m}^{3}$ \\
\hline
\end{tabular}

\begin{tabular}{|l|l|}
\hline $\begin{array}{l}\text { Interface } \\
\text { characteristics }\end{array}$ & Value \\
\hline Normal stiffness & $3^{*} 10^{11} \mathrm{kN} / \mathrm{m}$ \\
\hline Shear stiffness & $3^{*} 10^{11} \mathrm{kN} / \mathrm{m}$ \\
\hline Cohesion & $0 \mathrm{kPa}$ \\
\hline Friction angle & $28^{\circ}$ \\
\hline
\end{tabular}

As in the experimental centrifuge tests, a pressure equal to the soil pressure at rest is applied to maintain the stability of the tunnel face. This pressure is taken equals to the experimental value (i.e. $200 \mathrm{kPa}$ ). Then the model is subjected to an acceleration of $50 \mathrm{~g}$. Finally the ultimate active tunnel pressure is found by gradually decreasing the internal pressure until the failure of the soil mass nearby the tunnel face occurs. This means that a stress-controlled approach is used for the computation of the tunnel ultimate pressure.

THE NUMERICAL RESULTS 
As mentioned in the previous section, a stress-controlled approach is used to compute the active tunnel pressure. The computation is performed for the case $C / D=0.5$, where $\mathrm{C}$ and $\mathrm{D}$ are respectively the tunnel cover and the tunnel diameter. Several gradually decreasing pressures are successively applied to the tunnel face until failure or plastic flow occurs in the soil. At each pressure, several cycles are performed until a steady state of static equilibrium or plastic flow is developed in the soil. The plastic flow is achieved when both conditions are satisfied as the number of cycles increases:

(i) small values of the unbalanced forces for all nodes of the mesh;

(ii) a non-constant continuously increasing displacement of a specific point in the soil mass. In this paper, the horizontal displacement of the tunnel center is considered for this analysis.

The highest pressure corresponding to this state of plastic flow is called the active tunnel pressure (failure pressure). Notice that for smaller values of the tunnel pressure, a constant displacement of the tunnel center is obtained as the number of cycles increases (figure 2). This indicates that a steady state of static equilibrium (i.e. no failure or plastic flow) is obtained in those cases. From this figure, one can see that the active tunnel pressure is obtained for $\sigma_{t}=15 \mathrm{kPa}$ for which a non-constant continuously increasing displacement is obtained as the number of cycles increases.

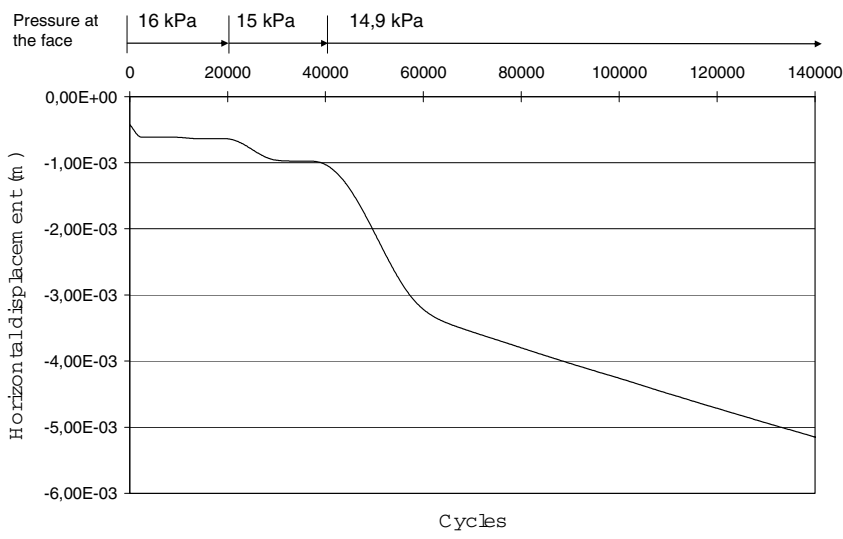

\section{FIG. 2 Horizontal displacement at the center of the tunnel face versus the number of cycles in FLAC ${ }^{3 \mathrm{D}}$}

An alternative and equivalent approach to identify the state of failure or plastic flow considers (i) the velocity of the tunnel center (horizontal velocity in the present paper) as shown in figure 3 and (ii) the condition on the unbalanced forces. For the active tunnel pressure, the velocity of the tunnel center does not decrease to zero with the number of cycles indicating a non-constant displacement of the tunnel center with the number of cycles (i.e. there is no steady state in this case). However, this velocity decreases to zero (which corresponds to a constant displacement) when the steady state of static equilibrium is obtained indicating that the failure does not occur in those 
cases. Notice however that the first approach is preferable since it gives information about the value of the tunnel center displacement for the different tunnel pressures.

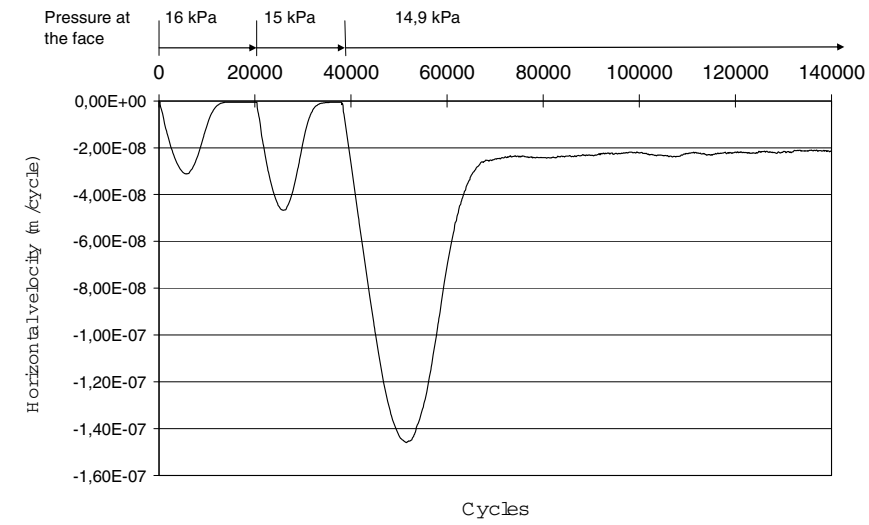

FIG. 3. Horizontal velocity at the center of the tunnel face versus the number of cycles in FLAC $^{3 \mathrm{D}}$

\section{COMPARISON WITH OTHER RESULTS}

The results of the active and passive pressures obtained from the numerical simulations using FLAC ${ }^{3 \mathrm{D}}$ are compared in figures 4 and 6 with those given by Leca and Dormieux (1990) and Soubra (2002) using the multiblock mechanism in limit analysis.

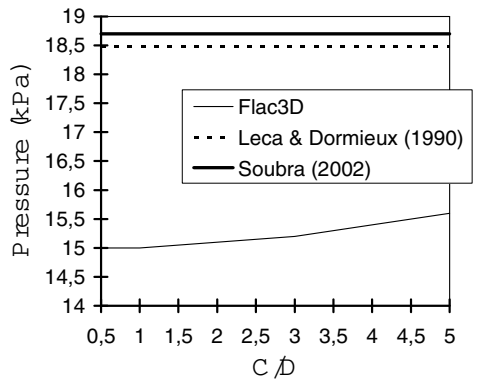

FIG. 4. Failure pressure versus C/D (collapse case) - comparison between the kinematical approach (Leca and Dormieux 1990 and Soubra 2002) and FLAC ${ }^{3 \mathrm{D}}$

Concerning the collapse case, the pressures calculated with FLAC $^{3 \mathrm{D}}$ are smaller than those given by the kinematical approach. A maximum difference of about $20 \%$ for 
$\mathrm{C} / \mathrm{D}=0.5$ is obtained. This difference could be related to the a priori assumption concerning the form of the failure mechanism chosen by Soubra (2002). The intersection between the cone adjacent to the tunnel face in the multiblock mechanism and the tunnel face is an ellipse. This surface represents the zone of the face concerned by failure. In the numerical simulations, the entire tunnel face is concerned by failure (figure 5). This may explain the difference between the ultimate pressures computed by the two approaches in the active case.

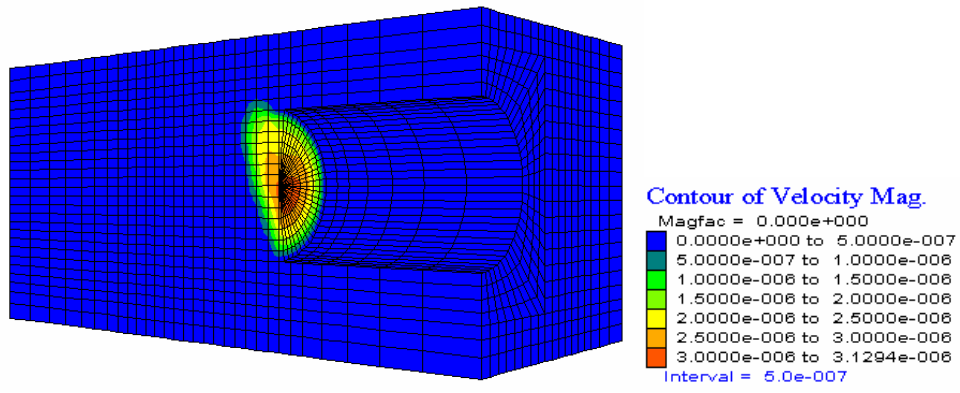

FIG. 5. Velocity field, collapse case, $C / D=0,5$

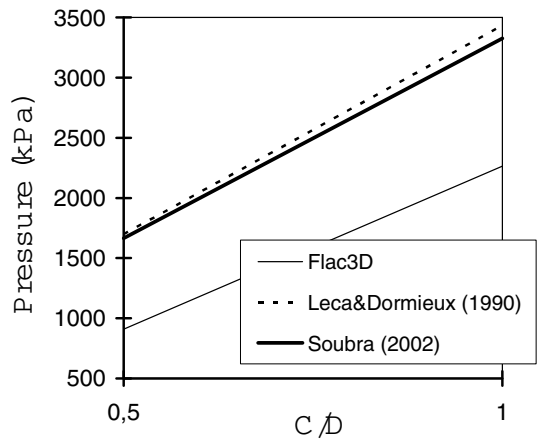

FIG. 6. - Failure pressure versus C/D (blow-out case) - comparison between the kinematical approach (Leca and Dormieux 1990 and Soubra 2002) and FLAC ${ }^{3 D}$

For the passive case, the ultimate passive pressures calculated by FLAC ${ }^{3 \mathrm{D}}$ are smaller (maximum difference of $40 \%$ ) than those provided by the kinematical approach. This may be explained by the shape of the failure considered by the multiblock mechanism at the tunnel face. Figure 7 shows that in the blow-out case, only the upper-half of the tunnel face is concerned by failure. However, the multiblock mechanism in limit analysis considers an ellipse whose great axis is vertical and equal to the tunnel diameter. 


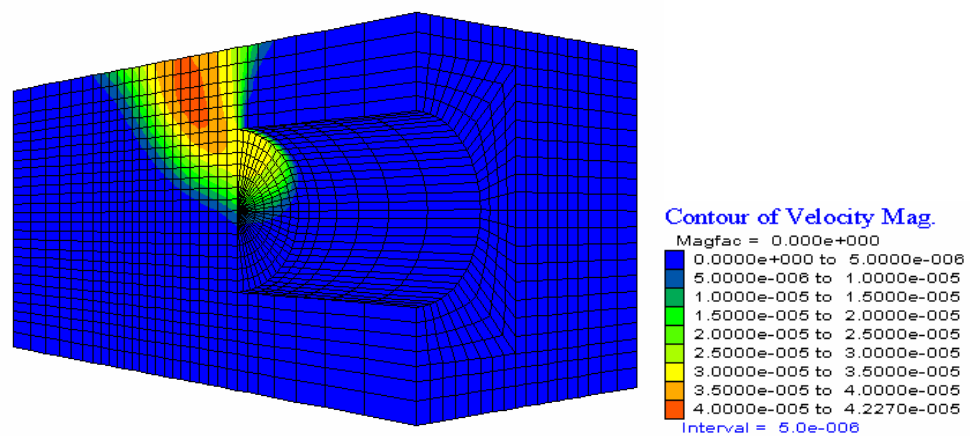

FIG. 7. Displacement velocity field, blow out case, $C / D=0,5$

Table 2 shows the comparison between the results of (i) the present numerical simulations, (ii) the kinematical approach and (iii) the centrifuge results for the following configuration: $\mathrm{C} / \mathrm{D}=2, \varphi=42^{\circ}, \psi=15.3^{\circ}, \gamma=15.7 \mathrm{kN} / \mathrm{m}^{3}$ where $\gamma$ is the soil unit weight. The solutions by Leca and Dormieux (1990) are not presented since the present upper-bound solutions by Soubra (2002) are better (i.e. greater) than the ones of Leca and Dormieux (1990).

The results given by the kinematical approach are not in good agreement with those obtained by the centrifuge tests (difference of about $30 \%$ ). This confirms that the failure mechanism used in this approach is not adequate to calculate the limit pressure of the tunnel.

Table 2: Comparison between the present results and those of the centrifuge tests and the upper-bound solutions by Soubra (2002)

\begin{tabular}{|c|c|c|c|}
\hline Authors & $\begin{array}{c}\text { Centrifuge tests - Al } \\
\text { Hallak (1999) }\end{array}$ & $\begin{array}{c}\text { Kinematical approach } \\
\text { (Soubra 2002) }\end{array}$ & $\begin{array}{c}\text { Numerical } \\
\text { simulations }\end{array}$ \\
\hline$\sigma_{t}[\mathrm{kPa}]$ & 8 & 5.8 & 6.8 \\
\hline
\end{tabular}

\section{CONCLUSIONS}

It was shown in this paper that the kinematical approach does not take into account with accuracy the failure shape at the tunnel face. In the collapse case, the entire surface of the face is at failure. However, the kinematical approach considers only an elliptical surface. In the blow out, the numerical simulations have shown that only the upper-half of the tunnel face is concerned by failure. However, an ellipse with a great vertical axis equal to the tunnel diameter is taken into account in the kinematical approach. Thus, it seems necessary to develop new failure mechanisms in limit analysis in accordance with the experimental and numerical findings. 


\section{REFERENCES}

Al Hallak R. (1999). "Etude expérimentale et numérique du renforcement du front de taille par boulonnage dans les tunnels en terrains meubles.", $\mathrm{PhD}$. thesis, Paris, Ecole Nationale des Ponts et Chaussées, 283 p.

Anagnostou, G. (1996). "Face stability in slurry and EPB shield tunnelling.", Proc. of the Int. Symposium on geotechnical aspects of underground construction in soft ground, London, Rotterdam :Balkema, 453-458.

De Borst, R., Van den Broek, W., Groen, A. (1996). "Two and three dimensionnal numerical modelling of a guided pipe-jacking in soft soil.", Geotechnical aspects of underground construction in soft ground, London, $8 \mathrm{p}$.

Dias D., Kastner R., Maghazi M. (2002). "Slurry shield tunneling : simulation of the effect of slurry infiltration on the face stability." ACUUS 2002 - Urban Underground space : a ressource for cities, International conference, Turin (Italy), $10 \mathrm{p}$.

Gaudin, C. (2002). "Modélisation physique et numérique d'un écran de soutènement autostable, application a l'étude de l'interaction écran-fondation.", $\mathrm{PhD}$ thesis, LGCIE, INSA Lyon, 2002, 401p.

Gay, O. (2000). "Modélisation physique et numérique de l'action d'un glissement lent sur des fondations d'ouvrages d'art.", PhD. thesis, Laboratoire 3S, Grenoble 1, 291p.

Leca, E. and Dormieux, L. (1990). "Upper and lower bound solutions for the face stability of shallow circular tunnels in frictional material." Géotechnique, 40(4), 581-606.

Soubra, A. H. (2000). "Three-dimensional face stability analysis of shallow circular tunnels." International Conference on Geotechnical and Geological Engineering, Melbourne, Australia.

Soubra, A. H. (2002). "Kinematical approach to the face stability analysis of shallow circular tunnels." 8th International Symposium on Plasticity, Canada, British Columbia, 443-445. 